\title{
O RAP COMO PENSAMENTO POLÍTICO BRASILEIRO
}

Gabriel Delphino ${ }^{1}$

\section{Resumo}

O artigo é produto de um estudo político do rap e tem por objetivo descobrir se é possível considerar algumas das letras como parte do corpus do Pensamento Político Brasileiro. Para tanto, foi realizada uma análise de discurso de dois álbuns, um do grupo Racionais MC's e outro do rapper Emicida, em torno dos eixos "raça", "escravidão" e "subdesenvolvimento", relacionando-os com textos clássicos do pensamento político.

\section{Palavras-chave}

Pensamento Político Brasileiro. Racionais MC’s. Emicida. Rap. Raça.

\section{Introdução}

Desde sua popularização enquanto fenômeno urbano, a partir das décadas de 1980 e 1990, o hip-hop brasileiro tem sido objeto de inúmeras análises antropológicas e sociológicas. Com isso, também surgem interessados em pesquisar, com a tentativa de entender os pilares do movimento hip-hop, um dos seus elementos fundadores: o rap. Contudo, por mais qualificados que sejam esses estudos, em sua maioria, focam na parte antropológica e social do hip-hop, não propondo uma investigação mais profunda sobre o seu aspecto político.

Esses esforços de analisar o movimento é de suma importância para a compreensão da sociedade brasileira, sobretudo de segmentos historicamente marginalizados. A partir do momento em que ele surge, é protagonizado, e majoritariamente composto, pela comunidade de mulheres negras e homens negros, passando a ter uma relevância como manifestação política dessa população. Não obstante, por ser um gênero musical, a crítica à realidade acompanha as letras para além das fronteiras territoriais, unindo reivindicações de populações marginalizadas na América Latina e em lugares nos quais o hip-hop se faz presente.

O discurso crítico é marcado pela posição periférica que os indivíduos possuem em suas sociedades, o que fica evidenciado nas letras analisadas, visto que as reivindicações, os descontentamentos, as contradições e as injustiças são referências para uma juventude brasileira que, atualmente, tem o rap como segundo gênero preferido ${ }^{2}$, perdendo apenas para o funk. A hipótese deste trabalho é de que o rap, em alguma medida, reflete discussões caras à

\footnotetext{
${ }^{1}$ Graduado em Ciência Política pela UNIRIO.

${ }^{2}$ Entre jovens de 12 a 15 anos. Ver mais em 〈http://www.culturanascapitais.com.br〉. (Acesso em: 17 out. 2019 ).
} 
sociedade e poderia ser considerado parte do corpus do pensamento político brasileiro, com potencial para ser uma "porta de entrada" para reflexões e debates. Diante disso, foi priorizada a análise política do rap a partir da análise de discurso, como formulada por Orlandi (2011), que conecta a língua à exterioridade, ao sócio-histórico, interligada pela ideologia e pelo inconsciente, que constitui o sujeito.

Foram analisadas letras de dois álbuns específicos - Sobrevivendo no Inferno, do grupo Racionais MC's, e Sobre Crianças, Quadris, Pesadelos e Lições de Casa..., do rapper Emicida - procurando estabelecer pontos de diálogo entre as letras e textos clássicos do pensamento brasileiro a partir dos seguintes eixos temáticos: "raça” (MUNANGA, 1986; GONZALEZ 1983; CÉSAIRE, 1978; NASCIMENTO, 1978); “escravidão” (GONZALEZ, 1988; MOURA, 1983) e “subdesenvolvimento" (FERNANDES, 1978; BASTIDE, 1974).

O artigo, além desta seção introdutória, está dividido em outras quatro seções. A primeira trata sobre a literatura dedicada a estudar o rap e o seu discurso político; a segunda, sobre um resgate do que tradicionalmente é considerado como pensamento político brasileiro e o que poderia ser lido como tal; na terceira será feita a análise do discurso das letras, e a quarta e última seção está reservada às considerações finais.

\section{1) Rap e Política}

Como afirma Melucci (1994, apud DAYRELL, 2002), devemos sempre atentar às expressões juvenis, visto que essas podem ser a ponta do iceberg que expressa as tensões e contradições da sociedade em que vivem. Já foi observado que o funk faz parte disso e merece atenção. Vianna (1990) pontua que o funk carioca nasce de uma readaptação do funk norteamericano, misturado a uma gama de elementos da cultura popular diversa da periferia do Rio de Janeiro. O autor também destaca que o preconceito com o qual a "indústria" percebe esse gênero musical a impede de compreender a riqueza desse fenômeno social contemporâneo. Não foi diferente com o rap, que também foi influenciado com referenciais estadunidenses e agregou elementos culturais nacionais, criando um estilo brasileiro próprio, refletindo as demandas locais do país.

A amostra foi escolhida de forma não aleatória; analisar dois artistas da cidade de São Paulo se deve à pertinência de se pensar a questão racial na maior metrópole do país. A urbanização e o desenvolvimento na cidade são permeados por tensões raciais que, por sua vez, são expressas em um gênero musical que tem questões políticas como elemento 
estrutural. Tais particularidades são originadas nos conflitos do ambiente urbano e conferem ao rap um discurso racial afinado com as questões de seu tempo.

É notável a existência de uma intenção, por parte da academia, de avançar a análise do hip-hop nesse sentido. A literatura que se debruçou a compreender o fenômeno comprova que desde sua origem se trata de um movimento de discurso político. As variações residem na orientação da análise: ora literária, ora focada na compreensão da relação com movimentos sociais, até mesmo como a relação da periferia e construção de um antagonismo de classe no discurso (OLIVEIRA,2014; BERTELLI, 2012; FÉLIX, 2006; KEHL, 1999). A pluralidade de possibilidades de estudo que o rap proporciona é um reflexo de sua complexidade. Um exemplo recente da importância do aprofundamento desses estudos é a inclusão de um álbum do Racionais MC's, Sobrevivendo no Inferno, como leitura obrigatória para o vestibular da Universidade Estadual de Campinas (UNICAMP) ${ }^{3}$. É o reconhecimento de que as letras transmitem uma mensagem com que a sociedade — em especial a juventude - precisa ter contato. O álbum foi recentemente transformado em livro ${ }^{4}$, sendo uma referência de manifestação da realidade política e social do negro nos anos 1980/1990.

No artigo de Petrônio Domingues (2007), por exemplo, é presente a intenção de inserir o hip-hop no contexto do movimento negro e o compreender como um novo fator.

Trata-se de um movimento cultural inovador, o qual vem adquirindo uma crescente dimensão nacional; é um movimento popular, que fala a linguagem da periferia, rompendo com o discurso vanguardista das entidades negras tradicionais. Além disso, o hip-hop expressa a rebeldia da juventude afrodescendente, tendendo a modificar o perfil dos ativistas do movimento negro; seus adeptos procuram resgatar a autoestima do negro, com campanhas do tipo: Negro Sim, Negro 100\%, bem como difundem o estilo sonoro rap, música cujas letras de protesto combinam denúncia racial e social, costurando, assim, a aliança do protagonismo negro com outros setores marginalizados da sociedade. (DOMINGUES, 2007, p. 119-120).

O autor também propõe que, apesar de incipiente no debate, o hip-hop seja a partir dali um novo elemento para estudiosos que se dedicam a estudar o movimento negro.

Com o passar do tempo, essa nova abordagem interpretativa se mostrou sólida; contudo, ainda há espaço para compreensão desse fenômeno não apenas em matéria de movimento social, mas também em seu discurso racial e político. Sobre essa relação, Teperman (2015) afirma que, desde o surgimento, nos Estados Unidos da América (EUA), o rap se vê conectado com as pautas de luta social reivindicadas pelo movimento negro.

\footnotetext{
3 Cf. <https://www.unicamp.br/unicamp/clipping/2018/05/24/racionais-no-vestibular>. (Acesso em: 17 out. 2019).

4 Cf.<https://www1.folha.uol.com.br/ilustrada/2018/11/obra-prima-dos-racionais-mcs-sobrevivendo-no-inferno-viralivro-apos-ser-exigido-em-vestibular.shtml>. (Acesso em: 05 nov. 2019).
} 
Nesse sentido, é preciso considerar um aspecto crucial dessa manifestação: sua ligação com as lutas do chamado movimento negro. Se a partir do fim dos anos 1980 o rap tendeu a se politizar, particularmente no que diz respeito às várias e perversas formas da desigualdade social e racial, nos anos anteriores as letras de rap não tratavam especialmente desses temas. Nem por isso o gênero deixava de ser um forte estruturador de movimentos pela valorização da identidade negra: a música, a dança, o estilo de se vestir são por si só produtores de significado. (TEPERMAN, 2015, p. 27).

Essa particularidade, de relação umbilical com pautas políticas e sociais, é o que torna o rap um movimento complexo e intrigante a ser estudado nos EUA, no Brasil e em outros países nos quais o gênero se faz presente, pois seu elemento de união mais significativo é o caráter contestatório da realidade. Paul Gilroy (2001), por exemplo, vai além ao buscar os processos de produção de uma identidade negra, em situação de diáspora, a partir das composições musicais chamadas de black music. Localizando essa questão no Reino Unido, ele observa que:

O estilo, a retórica e a autoridade moral do movimento dos direitos civis e do Poder Negro sofreram destinos similares. Eles também foram desvinculados de seus marcadores étnicos originais e de suas origens históricas, exportados e adaptados, com evidente respeito, mas pouco sentimentalismo, as necessidades locais e climas políticos. (GILROY, 2001, p. 175).

Portanto, o autor argumenta que, a partir das músicas, se desconstruiu a origem local de cada uma das reivindicações expostas e se construiu um status global. Isso ocorre pela existência de:

um fundo comum de experiências urbanas, pelo efeito de formas similares — mas de modo algum idênticas — de segregação racial, bem como pela memória da escravidão, um legado de africanismos e um estoque de experiências religiosas definidas por ambos. Deslocadas de suas condições originais de existência, as trilhas sonoras dessa irradiação cultural africanoamericana alimentaram uma nova metafísica da negritude elaborada e instituída na Europa e em outros lugares dentro dos espaços clandestinos, alternativos e públicos constituídos em torno de uma cultura expressiva que era dominada pela música. (Ibid., p. 175).

Já Boaventura de Sousa Santos se reinventou lançando o livro Rap Global, que estruturalmente é escrito em forma de rap e sugerido pelo autor a ser lido com o ritmo na cabeça (SANTOS, 2010). Assinado por "Queni N.S.L. Oeste”, heterônimo rapper do autor que vive na periferia de Lisboa, ele tem a intenção de realizar uma crítica à sua realidade. Sobre a criação do heterônimo, Santos afirma:

Tenho escrito cientificamente muito sobre a modernidade ocidental e tenho criticado sistematicamente os modos como ela, supostamente autolegitimada por uma promessa exaltante de emancipação, se transformou numa matriz de regulação e dominação social que assumiu três formas principais: o capitalismo, o colonialismo e o socialismo burocrático. Ora isto, que 
pretende dizer muito, deixa muito por dizer. Onde estão as pessoas e os seus dramas íntimos; as lutas de resistência e as resistências na luta; a criatividade moderna entre a loucura, a violência e o fanatismo; (...) Ora, nada disto pode ser dito academicamente (mesmo que o queira descrever em prosa) se o meu único objeto experimental for eu mesmo. É deste limite e do inconformismo perante ele que nasce o Rap como nasceram os meus livros anteriores de poesia. ${ }^{5}$

Para o autor, o questionamento do porquê os jovens não participarem da política, mesmo sendo protagonistas do melhor discurso de protesto nas sociedades atuais $\longrightarrow$ o hiphop - foi o que o motivou. É a partir disso que ele buscou misturar filosofia e sociologia com a cultura urbana e o rap $^{6}$.

No Brasil não foi diferente. A música "The Message" de Grandmaster Flash foi uma das pioneiras nos EUA a transferir uma mensagem política por meio da letra em seu país. Ao chegar aos ouvidos de Thaíde ${ }^{7}$, este afirmou que "havia algo por trás daquilo" mesmo sem compreender o que a letra dizia, percebendo que carregava uma mensagem que os MC's originais se preocuparam em passar a quem escutava (ALVES, 2004). Essa relação entre a política e o rap não se dá de forma inorgânica; ao contrário. Todas as pautas e questões são originadas e pensadas a partir da relação orgânica entre os rappers e o segmento social em que estão inseridos. Não estritamente em relações com a política tradicional, mas, como pontua Denis (2002, apud OLIVEIRA, 2015) ao discutir engajamento na literatura, "um escritor engajado seria, em resumo, um autor que 'faz política' em seus livros”, raciocínio que seria apropriado igualmente ao rap (OLIVEIRA, 2015).

Desse ponto em diante, o rap no Brasil estreitou progressivamente os laços com seu discurso político. O conhecimento - denominado "o quinto elemento" por Afrika Bambaataa - passava a ser o ponto de união das rimas que surgiam nas batalhas, principalmente na estação de metrô da São Bento, em São Paulo. Ali se reuniam vários artistas na intenção de realizar diversas atividades relacionadas ao hip-hop, como inicialmente o breakdance e posteriormente batalhas de rima. Apesar de até hoje existir uma natural incerteza de quando realmente surge o rap no Brasil, a data reside entre os anos 1980 e início dos anos 1990. Em um contexto de crise econômica, adicionado à condição já marginalizada do negro na

\footnotetext{
${ }^{5}$ Ver mais em CONDE, Miguel, e SANTOS, Boaventura de Souza. "Boaventura de Sousa Santos fala sobre "Rap Global'”. O Globo, 24/07/2010. Disponível em:<http://oglobo.globo.com/blogs/prosa/posts/2010/07/23/boaventura-de-sousa-santos-fala-sobre-rapglobal310530.asp>. (Acesso em: 17/11/2019).

${ }^{6}$ Ver mais em <https://filosofiapop.com.br/texto/o-grito-e-o-escudo-do-oprimido-o-rap-global-de-boaventuracomo-ekfrase/\#_ftnref2>. (Acesso em: 17/11/2019).

${ }^{7}$ Altair Gonçalves (São Paulo, cinco de novembro de 1967), mais conhecido pelo seu nome artístico de Thaíde, é um rapper, compositor, produtor, apresentador e ator brasileiro.
} 
sociedade, mais uma nova forma de arte, na qual o principal elemento era a difusão de conhecimento em uma estética própria de revolta periférica, era quase inevitável a politização do discurso e o uso da arte para interferir nessa realidade político-social. Dayrell (2002) argumenta que o conteúdo poético tende a refletir a realidade concreta com a qual cada jovem tem contato, elaborando sua vivência em uma postura de denúncia das condições do cotidiano. O rap, portanto, poderia ser visto como uma crônica da realidade da periferia, na qual os autointitulados "porta-vozes" da periferia se atribuem a missão de "conscientizar os caras".

\section{2) O Pensamento Político Brasileiro}

No que tange ao debate sobre pensamento político, deve-se observar que mesmo sua própria existência não é um consenso, de modo que o Brasil seria incapaz de produzir um pensamento político próprio. Ricupero (2007, p. 31) argumenta que "não é evidente que um país como o Brasil seja capaz de criar um pensamento político e social que dê conta de suas condições particulares”. Já Faoro (1987), ao pontuar que não existe, o justifica com a falta de um quadro cultural autônomo e uma sociedade capaz de moldá-la. Interpretação essa que se nutre no pensamento do próprio autor de que a dominação do Estado por um "estamento burocrático-patrimonial" bloqueia o desenvolvimento de uma sociedade brasileira (PEREIRA; VEIGA, 2017, p. 2).

Em contramão a essa versão, surgem explicações que afirmam a existência do pensamento político brasileiro, fundamentando a crítica a essa abordagem como uma maneira inferiorizada de avaliar a produção teórica do seu país. Argumentar que não existe pensamento político no Brasil seria apenas uma das várias faces de uma "submissão" intelectual por parte das elites brasileiras que advoga pela incapacidade de países periféricos de produzirem teorias sólidas (LYNCH, 2013).

A partir disso, pode-se definir pensamento político de diferentes formas, como um tipo de análise política que homens com algum comprometimento com o público realizam. São mobilizadas todas as informações disponíveis para a construção dessas avaliações, extraindoas de diversas fontes, como dados econômicos, traços culturais, indicadores sociais e indicadores políticos (SANTOS, 1970). Há também a definição como algo que não é estritamente prático, nem teórico, habitando um espaço entre esses dois campos, acompanhando e refletindo a realidade de maneira crítica. Ele assim se manifestaria melhor 
por meio de novelas, poesia, mais do que no discurso político em si, se expandindo em todas as manifestações culturais (FAORO, 1987).

Interpretações mais recentes colocam que o estudo dessa área seria o cruzamento de variadas disciplinas, como antropologia política e a sociologia da arte; a história da literatura e a história da ciência; a história das mentalidades e a sociologia dos intelectuais; a filosofia e teoria política e social; e a história das ideias e das visões-de-mundo. Esse cruzamento é inevitável por conta do nosso desenvolvimento capitalista retardatário, no qual o tratamento da literatura, arte, ciências, ganha uma significativa dimensão política (BRANDÃO, 2005).

Portanto, a hipótese deste trabalho, a ser testada na análise das letras a seguir, é que as letras de rap podem ser incluídas nessa coletânea de textos que compõem o estudo do pensamento. As definições através das quais a área é constituída em nada impedem a inclusão; ao contrário, incentivam, sobretudo pela possibilidade em elucidar o discurso político que a arte pode propagar em suas obras no país.

\section{3) A Análise Das Letras}

Como afirma Thaíde, "há muitos tipos de rap, mas o rap de verdade tem um lado mais político" 8 . A ligação entre um e outro é umbilical no movimento. Desde sua origem na década de 1960 na Jamaica, até ser levado aos EUA na década de 1970, o rap assumiu um caráter combativo, contestador da política tradicional e da realidade em que se situava. Levado por jovens jamaicanos para bairros pobres de Nova Iorque, é um movimento originário da população negra, composto em sua maioria por negros, manifestando diretamente o pensamento negro de sua época.

No Brasil isso vai ocorrer de maneira explosiva no final dos anos 1980 e início da década de 1990, momento em que diversos artistas fizeram uso das letras para manifestar suas críticas à realidade.

Ele é uma importante via para adentrarmos no terreno dos conflitos, das tensões e do poder que opera desigualmente na vida social, conduzindo-nos a repensar os processos sócio-históricos no Brasil atual e as contradições que o cercam, mesmo quando a difusão do rap está associada, em alguma medida, à indústria cultural e, por isso, seja tachado de alienante. (OLIVEIRA, 2015, p. 27)

Entender esse debate é fundamental para construir a análise de discurso a partir das letras dos rappers e reconhecê-los como parte do pensamento. A periferia sendo capaz de produzir seu pensamento político a partir das suas reflexões da própria realidade é

\footnotetext{
${ }^{8}$ Cf. <https://www1.folha.uol.com.br/fsp/folhatee/fm09089915.htm>. Acesso em 10 out. 2019.
} 
fundamental para a compreensão de um país periférico como o Brasil. Portanto, o esforço desse trabalho é ressaltar não apenas o pensamento negro brasileiro, como também um pensamento crítico, focado na questão do subdesenvolvimento do país. Esse ponto é central para compreender a conexão do rap com a produção de um pensamento periférico, que pensa sua realidade a partir de suas próprias contradições, em constante contraste com o "centro" e validando suas diferenças (VALDÉS, 2014).

Iniciaremos pelo álbum do Racionais MC's. Este tem sido um dos mais estudados do gênero, tanto quanto o próprio grupo, portanto farei algumas observações que são relevantes para a pesquisa. Lançado em dezembro de 1997, o álbum se torna a consolidação do que o grupo já vinha realizando havia algum tempo, porém agora com um sucesso nacional explosivo. Tanto na estética quanto nas letras, o grupo apresentava uma revolta que misturava angústias de uma juventude negra marginalizada que não se via representada de outras formas. Não por acaso, virou um marco não apenas musical, mas um marco para a autoestima dos negros no Brasil. A filósofa Djamila Ribeiro afirma que:

Eles foram decisivos na minha formação política, como de fato eles refletirem criticamente sobre a realidade deles me forneceu muitos referenciais, para me pensar como mulher negra (...) foi uma época de despertar muito potente da minha visão de negritude. ${ }^{9}$

De fato a obra ressalta uma valorização do negro, assunto que já era comum na academia e no movimento negro. A questão racial já era estudada em diferentes frentes de interpretação, desde o racismo científico "à brasileira", passando pela exaltação do mestiço por Gilberto Freyre e a recepção da negritude no meio do século XX. Esse despertar da negritude é conectado diretamente com o movimento internacional literário de negritude, protagonizado por Aimé Césaire e Léopold Senghor, que buscaram valorizar tanto a cultura negra quanto o negro em si, até então ambos desvalorizados. Para Césaire, por exemplo, negritude seria o simples reconhecimento do fato de ser negro, aceitando seu destino, sua história e sua cultura, rejeitando o teor de desprezo que carregava no passado para assumir uma posição de orgulho nessa identificação (MUNANGA, 1986). Ao ser recebido no Brasil, especialmente por autores como Abdias do Nascimento e Guerreiro Ramos, o movimento se manteve em essência e, a partir disso, buscou inicialmente uma tentativa de integração do mesmo na sociedade. Posteriormente há uma virada no sentido da reação à essa realidade; o discurso estrutural e o combate não apenas ao racismo, mas à sociedade colonial e capitalista é construído contundentemente.

\footnotetext{
${ }^{9}$ Ver mais em: <https://www.youtube.com/watch?v=rrImxSr0mQo>. Acesso em04 out. 2019
} 
Cabe mais uma vez insistir: não nos interessa a proposta de uma adaptação aos moldes da sociedade capitalista e de classes. Esta não é a solução que devemos aceitar como se fora mandamento inelutável. Confiamos na idoneidade mental do negro e acreditamos na reinvenção de nós mesmos e de nossa história. Reinvenção de um caminho afro-brasileiro de vida, fundado em sua experiência histórica, na utilização do conhecimento crítico e inventivo de suas instituições golpeadas pelo colonialismo e pelo racismo. Enfim reconstruir no presente uma sociedade dirigida ao futuro, mas levando em conta o que ainda for útil e positivo no acervo do passado. (NASCIMENTO, 1980, p. 262-263, apud DOMINGUES, 2005, p. 193).

É com base nisso que a negritude se manifesta no rap. A união do povo africano no continente e em diáspora em torno de sua própria cultura e seus próprios conhecimentos são priorizados. A ligação do conflito racial às desigualdades econômicas nesse processo não só é explícita em todo o álbum dos Racionais, como em diversas outras obras do gênero no Brasil. Veremos aqui que, em Sobrevivendo no Inferno, os autores trazem para as letras uma proposta de identidade que rompe com uma tradição conciliatória, com um projeto de comunidade negra distante do projeto mestiço predominante até o momento. Toda a identidade nacional baseada na conciliação racial e de classe seria nesse álbum encerrada em prol de uma denúncia de um genocídio velado, com o discurso de violência contra a população mais pobre, que no Brasil é marcada racialmente. O explorado, então, são as características das tensões raciais, permeadas pelo recorte de classe, como podemos ver já no início do álbum, em "Capítulo 4, versículo 3", quando, ao descrever um "outro mano lá" que se vestia bem, tinha o respeito de todos, fazia tudo certo, porém

Começou a colar com os branquinho do shopping
(Aí já era) ih mano outra vida outro pique
Só mina de elite, balada vários drinque,
Puta de butique, toda aquela porra sexo sem limite
Sodoma e Gomorra
Faz uns nove anos
Tem uns quinze dias atrás eu vi o mano
Cê tem que ver... Pedindo cigarro pros tiozinho no ponto
Dente tudo zuado, bolso sem nenhum conto
O cara cheira mal, azia, sente medo
Muito louco de sei lá o que logo cedo.

A partir desse trecho é possível observar que, ao surgir o personagem identificado como branco, sua interação com o preto é conflituosa, oferecendo a ele uma vida a fim de desconstruir tudo que ele havia construído até então. O grupo conclui com "Agora não oferece mais perigo/Viciado, doente, fodido, inofensivo", e de fato, um preto que poderia ser um contestador de sua realidade, construindo uma vida saudável na medida do possível, acaba 
cedendo à oferta dos brancos e desperdiçando sua vida em busca de drogas. No final da canção, o autor comenta

$$
\begin{aligned}
& \text { Irmão, o demônio fode tudo ao seu redor } \\
& \text { Pelo rádio, jornal, revista e outdoor } \\
& \text { Te oferece dinheiro, conversa com calma } \\
& \text { Contamina seu caráter, rouba sua alma } \\
& \text { Depois te joga na merda sozinho } \\
& \text { E transforma um preto tipo A num neguinho. }
\end{aligned}
$$

Aí fica explícita a posição do autor, ao associar o demônio ao homem branco rico que oferece de tudo para tirar o caráter e o interior do preto, como um projeto, a fim de manter esse segmento sempre à margem da sociedade. Indo ao encontro do relato do Primo Preto no início da música de que " $60 \%$ dos jovens de periferia sem antecedentes criminais já sofreram violência policial/A cada quatro pessoas mortas pela polícia, três são negras/Nas universidades brasileiras/Apenas $2 \%$ dos alunos são negros/A cada quatro horas um jovem negro morre violentamente em São Paulo". Esses versos retratam a visão dos autores sobre uma realidade que se fazia presente em muitos outros lugares pelo país. Tanto que a literatura do pensamento negro já produzia, em cima dessas realidades, narrativas alternativas para essa população. Cabe aqui mencionar Nascimento (1978), que afirma:

Nesta teia, o afro-brasileiro se vê tolhido de todos os lados, prisioneiro de um círculo vicioso de discriminação - no emprego e na escola - e trancadas as oportunidades que lhe permitiriam melhorar suas condições de vida, sua moradia, inclusive. (...) o fator racial determina a posição social e econômica na sociedade brasileira. (NASCIMENTO, 1978, p. 101).

A relação exposta na música entre raça e classe reflete o pensamento negro, de maneira que ambos observam naquela realidade brasileira a impossibilidade do negro de ascender socialmente. De maneira que, como observado, além dos órgãos de poder, como o governo, as leis, o capital, as forças armadas e a polícia, as classes dominantes brancas têm fortes mecanismos de controle social e cultural, como o sistema educativo e de comunicação em massa, estando todos esses instrumentos a serviço dos interesses das classes no poder para destruir o negro como pessoa (NASCIMENTO, 1978, p. 112). Como Oliveira (2018, apud RACIONAIS MC'S, 2018) aponta, nessa música o objetivo maior é construir uma comunidade periférica, em uma convivência entre irmãos. O rap assumiria todas as complexidades dessa marginalidade e, a partir disso, a periferia criaria espaços emancipatórios.

Esse assunto também é explorado em outra música do álbum e, indo além, o relaciona com o passado escravocrata do país de forma mais explícita. Em "Diário de um Detento" (RACIONAIS MC'S, 2018), essa conexão é levada adiante, em uma narrativa que constrói o 
ambiente de um dos momentos mais marcantes do país: o massacre no Carandiru. Com o Estado brasileiro optando pelo seu esquecimento, a música funciona como uma preservação da memória social da população negra brasileira. Segundo a definição de Le Goff (1990), pode-se afirmar que a memória seria um elemento essencial do que se costuma chamar de identidade, tanto individual quanto coletiva, cuja busca é uma das atividades fundamentais dos indivíduos e das sociedades atuais. A música, portanto, mantém viva a memória de uma população que aos poucos tem que construir sua identidade tanto individual quanto coletivamente, visto que desde sempre o Estado e suas elites buscam apagar de diversas formas a história desse povo. Ela detalha o cotidiano no Carandiru e, consequentemente, o massacre ocorrido em 1992, coma autoria de um ex-detento do presídio, Jocenir, em parceria com Mano Brown e contribuições de outros presos.

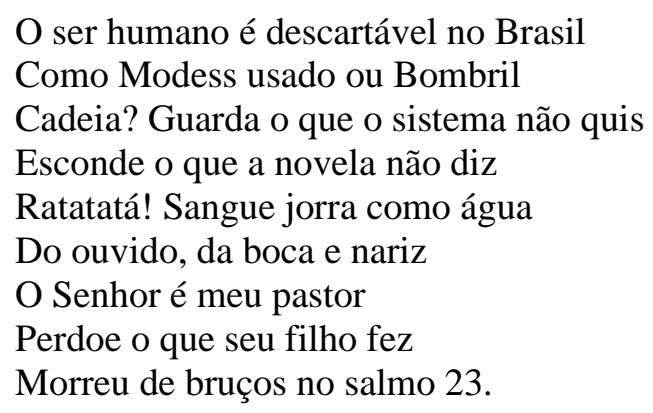

Essa passagem, ocorrida depois de toda a descrição do evento, expõe o pensamento dos autores sobre as condições do preso. A situação em que se encontra o preso, que, historicamente é de maioria negra, é atrelada novamente à ideia de que há um sistema de opressão que o coloca à margem do mesmo. Essa construção é eficaz quando pensamos o negro na sociedade capitalista, soando como uma denúncia a quem escuta, buscando uma tomada de consciência das relações socioeconômicas, fundamental para a superação dessa situação (FANON, 1952). Especialmente em um país como o Brasil, essa condição é escancarada ao ser analisada historicamente. Desde a abolição, esse segmento da sociedade é empurrado para fora do centro de desenvolvimento do país: seja em termos socioeconômicos, com uma liberdade que não passava do plano jurídico, tendo nas inter-relações as marcas da escravidão como demonstrado em Fernandes (1978); seja em termos de identidade, na qual a partir dessa busca pelo desenvolvimento e da imigração europeia a fim de ocupar os trabalhos recém-criados é desenvolvida a tese da "democracia racial", atribuída a Freyre (1933), em que se empurra o negro para fora dessa construção de identidade nacional, em prol de um "mestiço" que atenuaria os conflitos de classe e raça no país. 
Como foi priorizada a investigação de apenas esse álbum do grupo, não farei uma análise detida de nenhum outro, porém é relevante mencionar que em obras posteriores esses temas seguem sendo abordados, principalmente a questão do ser negro, criando uma linearidade em toda a carreira dos rappers.

Nessas obras, são explícitas as relações com os temas tratados historicamente pelo pensamento político. Raça, escravidão e subdesenvolvimento são eixos temáticos centrais congruentes às duas áreas, tanto no rap quanto no pensamento e interpretações do Brasil. Em seguida, veremos um álbum mais recente e serão observadas as diferenças deste para o anterior, lançado nos anos 1990. A diferença de tempo na escolha das obras é relevante para o estudo, visto que os eixos centrais não mudaram, mas a relação dos artistas com eles sofre alteração. O contexto em que as músicas foram feitas é significativamente diferente do anterior, pois nos anos 1990 temos um cenário político e social afetado pelo avanço do neoliberalismo e suas consequências. O cenário agora é pós-2010, com músicas construídas por pessoas que acompanharam o avanço da "onda rosa"10 no Brasil, bem como de um novo ciclo do movimento negro. A agressividade, que era uma marca nas letras dos Racionais em sua época, ainda permanece nessas obras, porém abre espaço para outros sentimentos. Ainda há a inquietude e os questionamentos, ambos baseados nas tensões raciais ainda presentes no Brasil contemporâneo; entretanto, as expressões não mais se resumem a isso. "Desde que eu comecei no rap até hoje eu vi o Capão mudar, eu vi o metrô chegar, vi as roupa, as visão sobre eles (...) eles se veem muito melhor que a gente se via", afirmou Brown em uma entrevista no ano de $2018^{11}$ sobre a relação entre o momento em que ele começa a carreira musical e a atualidade, não obstante ser essa a relação que transparece nas letras quando comparadas. Ele ainda complementa: "Eles têm a autoestima muito mais alta, tem uma visão intelectual e comportamental de raça, de autoestima, de beleza negra.”.

Observando a obra do rapper Emicida Sobre Crianças, Quadris, Pesadelos e Lições de Casa..., é possível perceber uma continuidade em questão de valorização do negro. Isso é algo que se manterá constante no rap, desde seu início até os dias atuais. Influenciado fortemente por uma viagem que o artista realizou ao continente africano enquanto construía o projeto, a obra foi finalizada com inúmeras referências ao local e ligações com uma ancestralidade comum entre os negros do continente e os diaspóricos. Aqui sim há uma presença substancial

\footnotetext{
${ }^{10}$ No início do século XXI a América Latina vivenciou a eleição de partidos e coalizões que se identificavam como esquerda e centro-esquerda. $\mathrm{O}$ fenômeno recebeu o nome de "maré rosa" em referência à ascensão de partidos de centro-esquerda no poder na Europa na década de 1990 (PANIZZA, 2006). O termo se manteve para a América Latina, com a existência da expressão "onda rosa" (PEREIRA, 2011) também sendo utilizada.

${ }^{11}$ Ver mais em: < https://www.youtube.com/watch?v=gMT9cXizDYQ>. Acesso em 27 mar. 2020.
} 
de uma exaltação de uma cultura negra universal, nos moldes do mencionado movimento literário da negritude do início do século XX. "Poetas, romancistas, etnólogos, filósofos, historiadores etc. quiseram restituir à África o orgulho de seu passado, afirmar o valor de suas culturas, rejeitar uma assimilação que teria sufocado a sua personalidade" (MUNANGA, 1986, p. 24). Essa rejeição da assimilação é o pilar central do álbum, pois cada faixa dialoga com essa questão de maneira distinta e valoriza suas ancestralidades. Enquanto em Sobrevivendo no Inferno a narrativa é construída com ênfase nos conflitos que o negro, no Brasil, enfrenta diariamente, adicionado a um apelo sincrético entre o catolicismo e as religiões afro-brasileiras, a obra de Emicida conta com um discurso de união entre o povo negro e suas conexões com o continente africano, rejeitando do início ao fim qualquer associação com uma religiosidade que não seja aquela ligada ao passado desse povo.

Na faixa "Amoras", que é um simples e curto diálogo que o artista afirma ser um poema para sua filha, ele canta que "as pretinhas são o melhor que há" e a conclusão da menina com "Papai, que bom, porque eu sou pretinha também". Essa virada valorativa do fenótipo do negro presente no discurso é uma das principais marcas do rap e aqui se faz presente, tal como argumentou Césaire (1978, p. 272): “O nosso papel (...) é anunciar e preparar a vinda daquele que detém a resposta: o povo, os nossos povos, libertos dos seus entraves; os nossos povos e o seu gênio criador finalmente desembaraçado daquilo que o contraria ou esteriliza". É nesse raciocínio que, ao recitar o poema à sua filha, Emicida busca no passado o preparo para o futuro da cultura e do povo negro, não negando essas civilizações, mas atribuindo a elas o seu valor.

Prosseguindo na obra, o rapper J. Ghetto inicia a faixa "Boa Esperança" com o refrão da seguinte forma:

\author{
Por mais que você corra irmão \\ Pra sua guerra vão nem se lixar \\ Esse é o X da questão \\ Já viu eles chorar pela cor do orixá? \\ E os camburão o que são? \\ Negreiros a retraficar \\ Favela ainda é senzala, jão \\ Bomba relógio prestes a estourar.
}

Já nesse segmento é perceptível a relação do discurso do autor com questões centrais no pensamento negro. Presente em todo o álbum, a exaltação de referências de religiões de matriz africana marca sua presença na faixa, evocado por uma provocação de que brancos não choram pela cor do orixá. De fato, as religiões africanas foram, por muito tempo, postas fora da lei pelo Estado brasileiro. Nina Rodrigues (1932, p. 197), elaborou que os africanos seriam 
"selvagens", associados a uma "consciência obscura" e a concepções baseadas em “totemismo". Em contrapartida, visões críticas a essa concepção foram construídas ao longo do tempo, visto que já em sua época era considerada ultrapassada. Guerreiro Ramos (1954) apontou que Nina Rodrigues buscava a aplicação de conceitos estrangeiros no Brasil, coisa que impossibilitaria qualquer compreensão da realidade nacional. Somado a isso o que chamou de "beatice", a admiração irrestrita dos povos europeus e da raça branca, tomado como exemplo a ser seguido por outros povos. Porém, como era predominante e oficial a religião católica no país, às afro-brasileiras restou apenas o sincretismo como único mecanismo de sobrevivência dessas práticas. Ao confirmar isso, Roger Bastide observa que esse sincretismo seria, simplesmente, uma máscara posta sobre o rosto dos deuses negros para benefício dos brancos (BASTIDE, 1974). A fim de combater esse tipo de visão que esse verso é mencionado no contexto da obra.

Essa questão religiosa, que não foi pautada dessa maneira na obra anteriormente analisada, se torna pilar central em um álbum de rap de 2015. A desconstrução desse sincretismo passa pela sua problematização, a fim de construir uma relação concreta do ser negro com sua realidade e ancestralidade. Sobre isso, Nascimento diz que:

É a linguagem de quem não compreende e desdenha. Incapazes de penetrar no sistema de pensamento por trás dos rituais tentam destruir tudo. Isto com a ajuda do sistema de pensamento europeu ocidental que se tem imposto através da coerção, às vezes até com o emprego da força armada, entre outros recursos, o que significa um elemento deveras subversivo dentro do chamado processo de assimilação, aculturação e sincretismo. (NASCIMENTO, 1978, p. 139).

Em seguida, a associação entre camburão da polícia e navio negreiro, favela e senzala, reitera a posição dos artistas sobre a condição marginal do negro na sociedade atual. Sendo mais bem explorada ao longo da música, essa é uma relação que se faz presente nos dois álbuns analisados, mostrando que, mesmo passado o tempo, o negro permanece como oprimido na base da sociedade.

No verso final do refrão temos, também, um indicativo de algo que retornaria posteriormente na canção. A menção ao barril de pólvora é a chave que associa essa opressão racial com a opressão de classe na sociedade brasileira contemporânea, marca característica do discurso do rap nacional, apontando como saída do problema apenas a canalização da raiva por meio revolucionário.

O tempero do mar foi lágrima de preto

Papo reto, como esqueletos, de outro dialeto

Só desafeto, vida de inseto, imundo

Indenização? Fama de Vagabundo 
Nação sem teto, Angola, Ketu, Congo, Soweto

A cor de Eto'o, maioria nos gueto

Monstro sequestro, capta três, rapta

Violência se adapta, um dia ela volta pu cêis.

Emicida continua a música versando sobre o processo de escravização do negro africano, trazendo importante destaque à questão da indenização pós-abolição. Mesmo abolido o sistema escravista, nenhum negro teve qualquer tipo de suporte do Estado ao ser liberto, sendo indenizados apenas os proprietários dos escravizados. Como pontua Clóvis Moura (1983):

O negro foi (...) lançado à periferia do sistema, não apenas para ficar no subemprego, no desemprego, na criminalidade do pobre e na prostituição, mas também, para ser dizimado biologicamente nos surtos de meningite, desidratação, tuberculose, raquitismo e outras doenças carenciais, além da sua destruição violenta por grupos racistas/repressivos como o "Esquadrão da Morte" cujas vítimas das suas ações criminosas são esmagadoramente negras. (MOURA, 1983, p. 12).

Conectado a isso se encontra o verso final do rapper, afirmando que a violência se adapta e ela se voltará contra os brancos dominantes. Cabe neste ponto ressaltar que essa música é a faixa que contém o tom mais agressivo e reivindicatório de toda a narrativa, na qual o autor exprime em palavras toda a raiva e indignação da posição que o negro ocupa no país. Não por acaso, como visto no refrão, é notada uma intenção reativa no cantor, como uma saída para o problema, que é o direcionamento dessa fúria em um processo revolucionário violento, devolvendo a violência sofrida em quem o fez sofrer todo esse tempo.

Essa relação do discurso violento retorna na faixa seguinte, que conta com a participação de outros artistas que trazem esse mesmo tom para a faixa. "Mandume", como o próprio autor afirmou, pode ser um hino da luta racial para quem se conecta com ele. Não por acaso, o nome da canção é referência ao último dos reis do povo Kwanyama. Mandume ya Ndemufayo foi o principal líder na luta contra a colonização portuguesa, oferecendo forte resistência em batalha. Também a presença da rapper Drik Barbosa é de importante destaque, visto que traz uma visão feminina desse grito de revolta negra.

Tanta ofensa luta intensa nega minha presença Chega! Sou voz das nega que integra resistência Truta, rima a conduta, surta, escuta, vai vendo Tempo das mulher fruta, eu vim menina veneno. 
Isso fica evidente ao observar já esse primeiro trecho, quando ela argumenta que a presença dela é negada mesmo no ambiente do rap, socialmente marginalizado. Autoproclamada uma "nega" da resistência, reafirma seu compromisso com a luta de um movimento que prioriza as pautas que interseccionam gênero, raça e classe. Ao se diferenciar das "mulheres fruta"12, ela demonstra que carrega e defende uma mensagem que sensibiliza quem ouve, não estando ali apenas pela aparência. Não obstante, Lélia Gonzalez (1983) afirma que é nesse ponto em que brancos absorvem da cultura e língua negra para falar em uma "cultura nacional". Transformam a bunda em objeto parcial por excelência da cultura brasileira, utilizam do charme, do olhar, da beleza da mulher negra para pintar um orgulho e transformar isso a prova de "democracia racial" no país, criando uma posição de desejo para que mulheres negras procurem ocupar esses espaços na cultura nacional. Qualquer negro que vá contra isso é reprimido e taxado racista, sendo nesse embate que a rapper se prontifica a entrar, quebrando essa narrativa em prol de um discurso próprio e autêntico, de acordo com sua posição de mulher negra periférica.

Mais adiante no verso, Drik faz uma referência que explicita também o caráter econômico da sua posição.

\section{Sistema é faia, gasta, arrasta Claudia que não Raia} Basta de Globeleza, firmeza? Mó faia.

Aqui ela traz uma referência ao caso de Claudia Silva, que enquanto comprava pão na favela onde morava, no Rio de Janeiro, em 2014, foi baleada por um Policial Militar. Entretanto, ao ser "socorrida" por uma viatura, a porta se abriu e a vítima foi arrastada no asfalto por cerca de 350 metros com o carro em movimento. Em seguida, ao mencionar "Claudia que não Raia", faz referência o sobrenome de Claudia Raia, atriz famosa, rica e branca, afirmando que o sistema mira apenas em corpos específicos da sociedade, na qual a chance de uma situação dessas ocorrer é substancialmente maior se a Claudia em questão for preta e pobre. Ademais, ainda chama atenção à Globeleza, como assinalado anteriormente, que é uma posição em que a mulher negra foi designada a ocupar na cultura e que representa uma característica do racismo brasileiro, a sexualização como forma de integração simbólica do negro no corpo social. Encerrando sua estrofe, a cantora novamente se reivindica como

\footnotetext{
12 "Mulheres frutas" é o nome que denomina um fenômeno do funk carioca nos anos 2000, no qual dançarinas escolhiam uma fruta para atribuir ao seu nome "artístico", como "Mulher Melancia", "Mulher Melão". Conhecidas por suas danças e pelo tamanho de suas bundas adotavam as frutas para popularizar seus nomes e criar identificações. Ver mais em <https://web.archive.org/web/20090515115324/http://www.tribunaimpressa.com.br/Conteudo/Mulheres-fruta-roubam-a-cena-no-funk-nacional,96810,60038>.
} 
parte do feminismo negro, dando atenção especial a essas mulheres que, como ela, se encontram inseridas nessas dois eixos de desigualdades, tal como escrita por Gonzalez (1988):

É importante insistir que no quadro das profundas desigualdades raciais existentes no continente, se inscreve, e muito bem articulada, a desigualdade sexual. Trata-se de uma discriminação em dobro para com as mulheres nãobrancas da região: As amefricanas e as ameríndias. O duplo caráter da sua condição biológica - racial e sexual — faz com que elas sejam as mulheres mais oprimidas e exploradas de uma região de capitalismo patriarcal-racista dependente. Justamente porque esse sistema transforma as diferenças em desigualdades, a discriminação que elas sofrem assume um caráter triplo, dada sua posição de classe.(GONZALEZ, 1988, p. 17).

Outra diferença notável entre os dois álbuns é a presença de uma exaltação à mulher negra e o enfoque nas desigualdades específicas que esse segmento sofre. Por exemplo, na faixa inicial, "Mãe", o trecho "Vai dar mó treta/Quando eu disser que vi Deus/E ele era uma mulher preta" é simbólico, pois esta é comparada a uma figura divina. Nesse momento a mulher ganha uma visibilidade que em outras gerações ocorreria com mais dificuldade.

Toda essa narrativa proposta pelo álbum elucida, do início ao fim, as preocupações do jovem artista de construir uma reintegração da população negra brasileira em torno da sua própria cultura. O resgate de referências, tanto culturais e religiosas de origem africana, quanto de casos contemporâneos de desigualdades e opressão sofridos por uma parcela da população, tem seu propósito e não foge a questões que o pensamento político se esforça em compreender.

Após a reflexão dos artistas sobre suas realidades, as observações feitas por Cardoso (1985) se revelam ainda mais atuais, visto que, apesar de alguns avanços, a situação não se alterou de maneira significante, já que, através do rap, o negro então busca, conforme salientado pelo autor, trilhar outros caminhos para a oficialização do seu próprio mundo, assumindo o comando de a iniciativa de acabar com a miséria econômica e filosófica, tomando a responsabilidade pelos seus próprios destinos.

\section{4) Considerações Finais}

O trabalho aproxima dois álbuns de rap com diversos autores do "cânone" do pensamento político brasileiro, bem como propõe diálogos críticos entre eles. E a partir do que foi observado, é possível afirmar que sim, o rap poderia ser incluído no corpus do Pensamento Político Brasileiro. A conexão com os eixos (raça, escravidão e desenvolvimento) é patente nas letras, ao abordarem questões como daqueles que pensaram e ainda pensam o Brasil, buscando compreender e explicar a formação política brasileira. 
A primeira obra analisada (Racionais MC's) é marcada por um discurso mais explícito, com denúncias enfáticas sobre a violência racial e desigualdade econômica. No mesmo sentido, a segunda obra (Emicida) traz também o discurso de construção de uma união afrodiaspórica e da interseccionalidade entre gênero, raça e classe. A diferença temporal, o contraste entre os contextos políticos em que os dois álbuns foram produzidos e a trajetória individual dos artistas se revelou como uma possível explicação para a diferença entre as abordagens dos eixos, visto que, embora os temas tenham se mantido praticamente os mesmos, o enfoque em cada um dos eixos foi diferente.

Deseja-se com esse estudo contribuir para a compreensão sobre o que é o rap em sua complexidade. Embora essa tenha sido apenas uma breve análise sobre o discurso e pensamento, a riqueza que esse fenômeno demonstra não só nas letras, mas também nos espaços de cultura hip-hop, endossou sua importância. Como observa Ramos (1954), é necessário deixar abrir mão conceitos importados, estruturas externas para a compreensão do nacional, buscando entender os fenômenos nacionais a partir deles próprios. Há de se fazer o trabalho de ir até esses espaços buscando o entendimento do que há de tão rico, em todos os sentidos. Considerando que são letras produzidas, em sua maioria por membros da periferia, é possível compreender o rap, não apenas como gênero musical ou parte de um movimento cultural, mas também como integrante do debate político brasileiro. A análise das letras, refletindo o cotidiano das periferias brasileiras, são de extrema importância para a compreensão dessa realidade.

De fato, como observado por Nascimento (1978):

\begin{abstract}
Arte negro-africana na diáspora, enquanto marginal em relação à arte santificada pelas sociedades locais, simultaneamente mantém as características ditadas pela história, pelo ambiente e pelas culturas dos respectivos países escravocratas. Nunca deixa, porém, de conservar temas, formas, símbolos, técnicas e conteúdos africanos em sua função revolucionária de instrumento de conscientização. Sua essência é uma parte vital da criatividade africana. (NASCIMENTO, 1978, p. 204).
\end{abstract}

Nesse sentido, as obras analisadas não apenas possuem essa essência, mas cumprem também um papel de conscientização conforme (DAYRELL, 2002).Visto que estimula o jovem a refletir sobre si mesmo e sua condição social, contribuindo para a ressignificação das identidades daquele que é negro e pobre, criando uma forma própria dele intervir na sociedade. Sem imposição de uma única compreensão da realidade, mas como um convite ao pensamento de cada um dos que ouvem.

É essa relação das letras com a realidade concreta e o debate intelectual que possibilita que sejam consideradas parte do corpus. É um elemento do meio cultural que possui um 
fundo político, no qual se orienta uma crítica da sociedade e a busca pela mudança da mesma. Quem quer compreender como pensava a sociedade alemã no início do século XIX pode pesquisar as poesias de Goethe e o romantismo alemão. Quem quer entender como se deu a construção de uma unidade nacional no início do século XX no Brasil, pode pesquisar o Modernismo e as obras de Mário de Andrade. Do mesmo modo, quem quiser compreender como pensava o negro brasileiro dos anos de1980-2010, pode pesquisar as letras dos raps analisados, visto que traduzem marcações de um pensamento característico do seu tempo, com termos e significados para suas realidades. Mais do que isso, não apenas refletem sua época, mas refletem criticamente sobre ela, procurando intervir no espaço público. Nada mais próximo da contemporaneidade do Pensamento Político Brasileiro do que o rap. Talvez mais próximo do que a própria Ciência Política contemporânea e sua baixa capacidade crítica e de incidência na realidade.

\section{Referências}

ALVES, César. Pergunte a quem conhece: Thaíde. São Paulo: Labortexto, 2004.

BASTIDE, Roger. As Américas Negras: as civilizações africanas no novo mundo. São Paulo: Difusão Europeia do Livro/Edusp, 1974.

BERTELLI, Giordano Barbin. Errâncias racionais: a periferia, o RAP e a política. In: Sociologias, Porto Alegre, v.14, nº 31, p.214-237, 2012.

BRANDÃO, Gildo Marçal. Linhagens do Pensamento Político Brasileiro. In: Dados, Rio de Janeiro, v. 48, n 2, p. 231 a 269, 2005.

CARDOSO, Hamilton. Isso é conversa de branco. In: Lua Nova, São Paulo, v.2, no 3, p. 13 19, 1985.

CÉSAIRE, Aimé. Discurso sobre o Colonialismo. Lisboa: $1^{\text {a }}$ Ed. Livraria Sá da Costa Editora, 1978.

CHASE, Clifton "Jiggs" et al. The Message. In: Grandmaster Flash \& The Furious Five. The Message: Sugar Hill Records, 1982. 1 CD. Faixa 7.

DAYRELL, Juarez. O que é o rap e o funk na socialização da juventude. In: Educação e Pesquisa, São Paulo, v.28, nº 1, p. 117-136, jan./jun. 2002.

DOMINGUES, Petrônio. Movimento negro brasileiro: alguns apontamentos históricos. In: Tempo, Niterói, v.12, n² 23, p.100-122, 2007.

DOMINGUES, Petrônio. Movimento da negritude: uma breve reconstrução histórica. Mediações - Revista de Ciências Sociais, Londrina, v. 10, nº 1, p. 25-40, jan.-jun. 2005. 
EMICIDA; BEATZ, NAVE. Boa esperança. In: Emicida. Sobre Crianças, Quadris, Pesadelos e Lições de Casa...: Laboratório Fantasma/ Sony Music, 2015. 1 CD. Faixa 10.

EMICIDA; INQUÉRITO, Renan. Mãe. In: Emicida. Sobre Crianças, Quadris, Pesadelos e Lições de Casa...: Laboratório Fantasma/ Sony Music, 2015. 1 CD. Faixa 1.

EMICIDA. Amoras. In: Emicida .Sobre Crianças, Quadris, Pesadelos e Lições de Casa...: Laboratório Fantasma/ Sony Music, 2015. 1 CD. Faixa 4.

EMICIDA et al. Mandume. In: Emicida. Sobre Crianças, Quadris, Pesadelos e Lições de Casa...: Laboratório Fantasma/ Sony Music, 2015. 1 CD. Faixa 12.

FANON, Frantz. Pele negra, máscaras brancas. Salvador: EDUFBA, 2008.

FAORO, Raymundo. Existe um pensamento político brasileiro?. In: Estudos Avançados, São Paulo, v.1, nº 1, p.9-58, 1987.

FELIX, João Baptista de Jesus. Hip-hop: cultura e política no contexto paulistano. 2005. 206 f. Tese (Doutorado em Antropologia Social) -Faculdade de Letras e Ciências HumanasUniversidade de São Paulo, São Paulo, 2005.

FERNANDES, Florestan. A integração do negro na sociedade de classes. São Paulo: Ática, 1978.

FREYRE, Gilberto. Casa-grande \& senzala. 42 ${ }^{\mathrm{a}}$ Ed, Rio de Janeiro: Record, 2001.

GILROY, Paul. O Atlântico negro: modernidade e dupla consciência. Rio de Janeiro: Universidade Cândido Mendes, Centro de Estudos Afro-Asiáticos, 2001.

GONZALEZ, Lélia. Racismo e sexismo na cultura brasileira. In: Ciências Sociais Hoje, Brasília, ANPOCS nº 2, p. 223-244, 1983.

Por um feminismo afrolatinoamericano. In: Revista Isis Internacional, Santiago, v. 9, p. 133-141, 1988b.

KEHL, Maria Rita. Radicais, raciais, racionais: a grande fratria do rap na periferia de São Paulo. In: São Paulo em perspectiva, São Paulo, v.13, nº 3, p. 95-106, 1999.

LE GOFF, Jacques. História e memória. Campinas: Editora da UNICAMP, 1990.

LYNCH, Christian Edward Cyril. Por que pensamento e não teoria? A imaginação políticosocial brasileira e o fantasma da condição periférica (1880-1970). In: Dados, v. 56, n 4, p. 727-767, 2013.

MOURA, Clóvis. Brasil: raízes do protesto negro. São Paulo: Global Editora, 1983.

MUNANGA, Kabengele. Negritude: usos e sentidos. São Paulo: Autêntica, 2009.

NASCIMENTO, Abdias. O genocídio do negro brasileiro: processo de um racismo mascarado. Rio de Janeiro: Paz e Terra, 1978. 
OLIVEIRA, Roberto Camargos de. Rap e política: percepções da vida social brasileira. $1^{\mathrm{a} E d}$, São Paulo: Boitempo, 2015.

OLIVEIRA, Acauam Silvério de. O fim da canção? Racionais MC's como efeito colateral do sistema cancional brasileiro. 2015. 423 f. Tese (Doutorado em Literatura Brasileira) Faculdade de Letras e Ciências Humanas-Universidade de São Paulo, São Paulo, 2015.

ORLANDI, Eni Puccinelli. A análise de discurso e seus entre-meios: notas a sua história no Brasil. In: Cadernos De Estudos Lingüísticos,v. 42, p. 21-40, 2011.

PANIZZA, Francisco. La marea rosa. Análise de Conjuntura OPSA, 8. Rio de Janeiro: OPSA, 2006.

PEREIRA, Fabricio; VEIGA, Luciana. Pensamento Político Brasileiro In: BATISTA, Cristiane; ECHART, Enara. (Org.). Teoria e Prática da Política. $1^{\text {a }}$ Ed. Curitiba: Appris, v. 1, 2007, p. 147-162.

PEREIRA, Fabricio. Vitórias na Crise: trajetórias das esquerdas latino-americanas contemporâneas. Rio de Janeiro: Ponteio, 2011.

RACIONAIS MC's. Sobrevivendo no Inferno. $1^{\text {a }}$ ed, São Paulo: Companhia das Letras, 2018.

RACIONAISTV. Racionais: sobrevivendo no inferno por Djamila Ribeiro. 2018. (14m40s). Produção: Fabio Uehara. Disponível em: $<$ https://www.youtube.com/watch?v=rrImxSr0mQo>. Acesso em 04 out. 2019. (AUDIOVISUAL).

RAMOS, Alberto Guerreiro. O problema do negro na sociologia brasileira. In: Cadernos do Nosso Tempo, 2, jan./jun. 1954.

RICUPERO, Bernardo. Sete lições sobre as interpretações do Brasil. São Paulo: Alameda, 2007.

RODRIGUES, Raimundo Nina. Os africanos no Brasil. Rio de Janeiro: Centro Edelstein de Pesquisas Sociais, 2010.

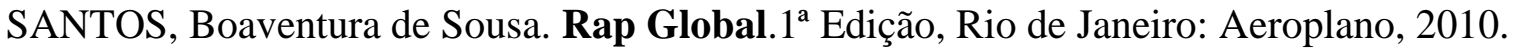

SANTOS, Wanderley Guilherme dos. Raízes da imaginação política brasileira. In: Dados, Rio de Janeiro, $\mathrm{n}^{\mathrm{o}}$ 7, p. 137-161, 1970.

TEPERMAN, Ricardo. Se liga no som: as transformações do rap no Brasil. $1^{\text {a} E d, ~ S a ̃ o ~ P a u l o: ~}$ Claro Enigma. 2015.

VALDÉS, Eduardo Devés. Pensamiento Periférico:Asia-África- América Latina-Eurasia y algo más. Una Tesis Interpretativa Global. Buenos Aires: CLASCO; IDEA-USACH, 2017. 
VIANNA, Hermano. Funk e Cultura Popular Carioca. In: Estudos Históricos, Rio de Janeiro. v. 3, no 6, p. 244-253, 1990.

\title{
RAP AS BRAZILIAN POLITICAL THOUGHT
}

\begin{abstract}
The article is the product of a political study of rap, which aims to find out if it is possible to consider some of the lyrics as part of the corpus of Brazilian Political Thought. To this end, a discourse analysis of two albums was carried out: one by the group Racionais MC's and another by the rapper Emicida, around the axes of "race", "slavery" and "underdevelopment", relating them to classic texts of political thought.
\end{abstract}

\section{Keywords}

Brazilian Political Thought. Racionais MC's. Emicida. Rap music. Race. 